\title{
DA PROPRIEDADE À MORADIA: BREVE ESTUDO SOBRE A EVOLUÇÃO CONSTITUCIONAL BRASILEIRA*
}

\section{FROM PROPERTY TO HOUSING: A BRIEF STUDY ON BRAZILIAN CON- STITUTIONAL EVO-LUTION**}

\section{João Carlos Souto ${ }^{1}$ Thiago Aguiar de Pádua ${ }^{2}$}

\begin{abstract}
RESUMO: A propriedade, conforme se verá nas linhas que se seguem, se apresenta, de longa data, como um direito fundamental, indispensável ao ser humano, seja ele individualmente considerado, seja na pluralidade da família. Integra aquilo que os norte-americanos alcunharam, ainda no crepúsculo do século XVIII, como the pursuit of Happiness, "busca pela Felicidade", o que demonstra o caráter central, fundamental e indispensável desse direito. A isso, em parte, se propõe o presente artigo, discorrer sobre a relevância do direito à propriedade, os primeiros documentos iluministas que lançaram um olhar sobre ele, sua evolução constitucional no Brasil, até a moradia ser elevada à condição de direito social.
\end{abstract}

Palavras-Chave: Brasil. Evolução constitucional. Direito de Propriedade. Constituições brasileiras. Direito a moradia. Direitos Sociais.

\footnotetext{
* Evolução constitucional tomando-se por fundamento as Constituições de 1824, 1891, 1934, 1946 e 1988 . Ficam excluídas da presente análise as "não democráticas” de 1937 e 1967/69. A de 1824 igualmente não foi democrática, contudo, restou incluída por se tratar da primeira Constituição do Brasil.

** Constitutional evolution based on the Constitutions of 1824, 1891, 1934, 1946 and 1988. The "non-democratic" of 1937 and 1967/69 are excluded from this analysis. The one of 1824 was also not democratic, however, it remained included because it was the first Constitution of Brazil.

${ }^{1}$ Doutorando e Mestre em Direito. Bacharel em Direito, Universidade Federal da Bahia. Estudou na Harvard Law School (PIL-1998); University of Delaware (95) e na Thomas Jefferson School of Law (2012). Professor de Direito Constitucional (Graduação e Pós). Foi Secretário de Estado de Justiça e Cidadania do Distrito Federal, de 01.01.2015 a 23.02.2016. Membro Consultor da Comissão Nacional de Relações Internacionais da Conselho Federal da OAB. É Procurador da Fazenda Nacional. E-mail: joao.souto@udf.edu.br. ORCID: https://orcid.org/0000-0003-2229-2975.

${ }^{2}$ Doutor e Mestre em Direito. Professor Doutor do Programa de Pós-Graduação (Mestrado) em Direito do UDF Centro Universitário do Distrito Federal. Membro do CBEC - Centro Brasileiro de Estudos Constitucionais. Membro das Comissões de Direito \& Literatura e Direito à Educação do Conselho Federal da OAB. Vice-Presidente da Comissão de Estudos Constitucionais e Membro da ANACRIM. Membro da ABPC - Associação Brasiliense de Processo Civil. Ex-Assessor de Ministro do Supremo Tribunal Federal. Poeta e Advogado. E-mail: professorthiagopadua@gmail.com. ORCID: https://orcid.org/0000-0003-3165-3058.
} 
ABSTRACT: Property, as will be seen in the following lines, has long been a fundamental right, indispensable to human beings, whether individually considered or in the plurality of the family. It is part of what Americans came to call, in the twilight of the eighteenth century, as the "pursuit of Happiness," which demonstrates the central, fundamental, and indispensable character of this right. In part, this article proposes to discuss the relevance of the right to property, the first Enlightenment documents that took a look at it, its constitutional evolution in Brazil, until housing (moradia) was elevated to social rights.

Keywords: Constitutional Evolution. Property Rights. Brazilian Constitutions. Right to Housing. Social Rights.

Sumário: 1. Introdução. 2. O direito à propriedade em um dos mais importantes documentos do iluminismo. 2. Constituição dos Estados Unidos e Declaração dos Direitos do Homem e do Cidadão de 1789. 3. O caráter fundamental do direito à propriedade. 4. Constituição de 1824. 5. Constituição de 1891. 6. A Constituição de 1934. 7. A Constituição de 1946. 8. A criação do Banco Nacional de Habitação. 9. Constituição de 1988. 10. Relevância do significado da "moradia". 11. Condições de moraria e desempenho escolar. 12. Conclusão. 13. Referências.

\section{INTRODUÇÃO}

O presente artigo, vocacionado a abordar um importante tema constitucional sub o pálio da perspectiva dogmática e de sua evolução ao logo de nossa tradição constitucional, cuida de refletir sobre o direito à moradia, desde sua inicial vinculação ao direito de propriedade.

Em linhas gerais, se por um lado existem visíveis laços com alguns aspectos que nossos coirmãos do norte atrelaram inicialmente à busca pela felicidade (that among these are Life, Liberty and the pursuit of Hapiness), por outro, a trajetória que liga propriedade e moradia, até esta última ser inserida com direito social na Constituição de 1988, fez a mesma travessia tortuosa, talvez o mesmo sonho que inculcava os ânimos daqueles que atravessaram o atlântico à bordo do Mayflower.

Seja num caso (trajeto da tradição constitucional), ou no outro (os Peregrinos de Southampton), animam as linhas deste artigo a abordagem sobre a importância do direito à propriedade, desde os documentos constitucionais mais importância de que se 
tem notícia, passando pelas inserções em nossas sucessivas constituições até chegarmos ao momento atual, no seio da Constituição cidadã, a carta que Ulysses brandiu em 1988 com a juventude de um menino, e a retórica de um tribuno experimentado, seguramente sabedor das dificuldades que enfrentaríamos para implementar todos os direitos fundamentais, inclusive o direito à moradia. Por este motivo, importa conhece-lo desde suas raízes mais remotas.

\section{O DIREITO À PROPRIEDADE EM UM DOS MAIS IMPORTANTES DOCU- MENTOS DO ILUMINISMO}

A Declaração de Independência das Treze Colônias inglesas na América é um clássico estudado na Ciência Política, História e no Direito, especialmente o Constitucional. Sua autoria ${ }^{3}$ é atribuída a Thomas Jefferson ${ }^{4}$, um dos founding fathers ${ }^{5}$ dos Estados Unidos e que mais tarde se tornaria seu terceiro presidente. Redigida em 1776 e assinada em 04 de julho daquele ano, tornou-se na "certidão de nascimento" da nova nação, algo raro na história dos povos, o nascimento de um país resultar de um texto muito bem escrito, fruto de reflexão madura e assinada por representantes (delegados) de 13 Colônias que decidiram romper definitivamente os laços com a antiga metrópole, senhora dos mares e potência militar de grosso calibre.

Jacques Derrida (2017, 1984 e 1986), ao analisar esta Declaração de Independência, ressaltou a característica de seu "golpe de força", e também o intrigante fato de

\footnotetext{
${ }^{3}$ The document, after heated debate, was finally approved by Congresso n July 4, 1776. Cut and occasionally altered by Adams, or Franlin, or the Congress iteslf, the Declaration is almost completely Jefferson's, and is undoubtedly the triumph and culmination of his early career. Cf. KOCH, PEDEN, 1998, p. xxi.

${ }^{4}$ Uma das figuras mais emblemáticas da História norte-americana. Escreveu a Declaração de Independência, foi embaixador dos Estados Unidos na França, Secretário de Estado, Vice-Presidente da República e em seguida Presidente da República por dois mandatos (1801-1809). Culto, rico e contrário ao controle de constitucionalidade em mãos do Judiciário; nesse particular pressionou esse Poder e especialmente John Marshall, autor do célebre voto no caso Marbury v. Madison (1803), origem do controle difuso. Sobre Jefferson consultar o já citado (KOCH, Adrienne e PEDEN, William) "The Life and Selected Writings of Thomas Jefferson", New York: The Modern Library, 1998. Sobre todos eles (Jefferson, Madison e a saga do julgamento do caso que inaugurou o judicial review) consultar (SOUTO, 2019), especialmente os Capítulos II e VII.

${ }^{5}$ A expressão founding fathers (pais fundadores) é largamente utilizada para se referir a todos os que participaram da construção do país, seja na luta pela Independência, seja na elaboração da Constituição de 1787.
} 
que "não se pode decidir se essa independência é estatuída ou produzida por este enunciado", além do aspecto relacionado a "indecidibilidade" inerente ao documento de declaração: "esta obscuridade, esta indecidibilidade entre uma estrutura performativa e uma estrutura constatadora, é exigida em ordem a produzir os efeitos desejados".

$\mathrm{E}$, ao fazer o resgate desconstrutivo, cita famosa anedota sobre o tema, na perspectiva de não ser a Declaração de Independência trabalho isolado e unitário:

\begin{abstract}
"Alguém, chamemos de Jefferson (mas por que não Deus?), desejou que a instituição do povo Americano devesse ser, pelo mesmo golpe, a ereção do seu próprio nome. O nome do Estado. Ele foi bem-sucedido? Eu não me arriscaria a dizer. Vocês ouviram a história antes de mim. Franklin queria consolar Jefferson sobre a "mutilação" (a palavra não é minha).

Ele contou ao colega uma anedota sobre um chapeleiro, na qual o chapeleiro imaginou inicialmente uma placa de sinalização para o seu comércio: a imagem de um chapéu, e próxima a ele uma inscrição: "Chapeleiro John Thompson, fabrica e vende chapéus à vista". Um amigo então sugere que ele apague a palavra "chapeleiro": quão adequado seria isso, já que a expressão "fabrica chapéus" não seria explícita o bastante?

Outro amigo então sugere que ele suprima a expressão "fabrica chapéus", já que seria indiferente aos consumidores quem produz, desde que eles gostassem do chapéu. Esta "supressão" é particularmente interessante, pois ela apaga a marca distintiva do fabricante. Um terceiro amigo, e são sempre os amigos quem exortam a supressão, sugere que ele economize na expressão "vende à vista", pois havia um costume naquele período no qual os pagamentos já deveriam ser em "dinheiro"; assim, no mesmo movimento, ele deveria apagar "vende chapéus", pois apenas um idiota acreditaria que os chapéus seriam doados gratuitamente.

Então, finalmente, a placa de sinalização passou a ostentar apenas uma imagem, sob o símbolo icônico na forma de um chapéu, e apenas o nome John Thompson, e nada mais. Alguém poderia ter imaginado outras coisas, como o nome próprio inscrito sob um guarda-chuva ou mesmo sob um par de sapatos." (DERRIDA, 2017)
\end{abstract}

Esse Documento encapsula valores iluministas, entre outros os da isonomia (all men are created equal), afirma que a raça humana ${ }^{6}$ é titular de direitos inalienáveis e irrenunciáveis (they are endowed by their Creator with certain unalienable Rights), como o direito à Vida, Liberdade e busca da Felicidade (that among these are Life, Liberty and the pursuit of Hapiness).

\footnotetext{
${ }^{6}$ A Era das Luzes não alcançou os escravos, muito embora constitua-se uma nódoa desse tempo, não se pode desconsiderar a relevância da Filosofia Iluminista.
} 
Embora não tenha natureza normativa o Documento "declarou" ao mundo de então que as 13 Colônias inglesas da América seguiriam o caminho que ele (documento) apontava, nesse sentido tem um valor principiológico incontestável. Mas quem "assina" o documento, com força de "assinatura", no sentido proposto por Derrida, é questão que permanece intrigante (DERRIDA, 2017).

Digna de nota a parte supra reproduzida que se refere ao direito à "Vida, Liberdade e busca da Felicidade"7. Aqui nos interessa o último deles, "busca da Felicidade", que se especula se refira ao direito de propriedade. É como pensa J. A. Corry, que inclusive identifica nessa passagem remissão (CORRY, 1951, p. 89) a John Locke, pensador inglês lido e já reverenciado nessa época, aliás, o próprio Jefferson o considerava um grande filósofo e afirmara que autores de Aristóteles à Locke foram elementares aos americanos do século XVIII. Afirmou, ainda, que não se fixou em nenhum livro específico ao escrever o Documento mais importante da História dos Estados Unidos, depois da Constituição de 1787. Importante lembrar nestas considerações preliminares, de natureza histórica e de Direito Comparado, que a Constituição dos Estados Unidos incorporou (emendas V e XIV) esses valores mencionados na Declaração de Independência.

\section{CONSTITUIÇÃO DOS ESTADOS UNIDOS E DECLARAÇÃO DOS DIREI- TOS DO HOMEM E DO CIDADÃO DE 1789}

Seguiu-se à Constituição norte-americana, que é de 1787, a Declaração dos Direitos do Homem e do Cidadão, editada na França, em 1789, que igualmente acolhe a propriedade como direito fundamental: “Art. $2^{\circ} \mathrm{O}$ fim de toda a associação política é a conservação dos direitos naturais e imprescritíveis do homem. Esses Direitos são a liberdade. a propriedade, a segurança e a resistência à opressão".

\footnotetext{
${ }^{7}$ Pursuit of Hapiness, ganhou, por assim dizer, "autonomia". Foi título de um comovente filme de Hollywood, estrelado por William Smith, baseado em fatos reais, a história de vida de .... Contudo, a "busca da felicidade" nessa película agasalhou a lógica de Wall Street, vale dizer, não era propriamente assegurar a propriedade, mas simplesmente construir fortuna rápida e relativamente fácil especulando na Bolsa de Valores (The New York Stock Exchange).
} 
Ainda com a Declaração dos Direitos do Homem e do Cidadão, confira-se o art. 17: "Como a propriedade é um direito inviolável e sagrado, ninguém dela pode ser privado, a não ser quando a necessidade pública legalmente comprovada o exigir evidentemente e sob condição de justa e prévia indemnização".

\section{O CARÁTER FUNDAMENTAL DO DIREITO À PROPRIEDADE}

Como se vê desde os primórdios do Constitucionalismo - assim entendido como o movimento iniciado em fins do século XVIII, que normatizou e tornou concretas ideias e princípios desenvolvidos no Iluminismo - a propriedade figurou entre os denominados direitos fundamentais, ao lado do direito à vida e às liberdades (de manifestação, de religião, de ir e vir, de imprensa, entre outras), o que demonstra a centralidade do tema.

Bem por isso as Constituições brasileiras têm acolhido o direito à propriedade em seus textos, sem homogeneidade, é verdade, mas com uma constância que bem revela a importância do tema, já percebido desde a Declaração de Independência dos Estados Unidos, conforme demonstrado. Os parágrafos seguintes acolhem breves comentários sobre cada uma das Constituições brasileiras, naquilo que diz respeito ao Direito de Propriedade.

\section{CONSTITUIÇÃO DE 1824}

Muito se pode dizer sobre a primeira Constituição brasileira, elaborada em uma época em que a França era o grande farol cultural do mundo, e, nessa condição, os experimentos políticos igualmente tinham grande prestígio entre os países de fora do Velho Continente.

Trata-se de uma Constituição sobre a qual se poderia dizer unique, porquanto serviu, por assim dizer, de laboratório para uma experiência constitucional jamais re- 
produzida em qualquer outra Lei Fundamental, seja no Brasil ou no exterior, com exceção da Constituição portuguesa, de 1826. Refiro-me ao Poder Moderador, que, no dizer de José Afonso da Silva, era "considerado a chave de toda a organização política, era exercido privativamente pelo Imperador, como chefe supremo da nação e sem primeiro representante, para que incessantemente velasse sobre a manutenção da independência, equilíbrio e harmonia dos demais poderes políticos (art. 98)" (SILVA, 1997, p. 77). Ainda sobre o Poder Moderador vale destacar a lição de Octaciano Nogueira:

\begin{abstract}
Efetivamente está aí, claramente descrito, o seu papel dominante. Pode-se mesmo dizer que o Poder Moderador moldou o regime político que tivemos nos 65 anos de duração da Carta de 24. É a sua concepção, em última análise, que impulsiona a monarquia constitucional no caminho de seu papel ativo, em contraste com o papel passivo das monarquias parlamentares. Chamado com muita propriedade de Poder Real, Poder Imperial, Poder Neutro ou Poder Conservador, a sua concepção é atribuída, por Jellinek (L'État moderne et son droit), a Clermont-Tonnerre e a Benjamin Constant. Na prática, porém, foi aplicado apenas no Brasil e esta é uma das singularidades da Constituição Política do Império. E, com tal amplitude que se exercia quer em relação ao Legislativo (nomeando os Senadores, convocando, prorrogando e adiando a Assembleia Geral; dissolvendo a Câmara, sancionando as proposições do Legislativo e aprovando e suspendendo interinamente as resoluções das Assembleias provinciais); quer em relação ao Executivo, (nomeando e demitindo livremente os Ministros de Estado); quer, finalmente, em relação ao Judiciário (suspendendo os Magistrados, perdoando e moderando as penas impostas aos réus por sentença, e concedendo anistia) (NOGUEIRA, 2012, p. 32).
\end{abstract}

No que diz respeito especificamente ao direito de propriedade a Constituição de 1824 estabelecia que (art. 133, V) os Ministros de Estado eram responsáveis (pelo que obrarem contra a Liberdade, segurança, ou propriedade dos Cidadãos). O artigo 179 trata da propriedade com mais vagar; primeiro no caput, para dizer que "a inviolabilidade dos Direitos Civis, e Políticos dos Cidadãos Brasileiros, que tem por base a liberdade, a segurança individual, e a propriedade, é garantida pela Constituição do Império". Em seguida, o inciso VII desse artigo estabelece a inviolabilidade da casa, com redação semelhante a que se verifica na Constituição de 1988. A de 1824, nesse particular, tem a seguinte: "de noite não se poderá entrar nela, senão por seu consentimento, ou para 
o defender de incêndio, ou inundação; e de dia só será franqueada a sua entrada nos casos, e pela maneira, que a Lei determinar."

Digno de registro que as garantidas do inciso VII se dirigem à moradia, no sentido de local onde a pessoa vive sozinha ou com sua família, não a qualquer propriedade. Adiante, ainda no art. 179, o inciso XXII garante o direito de propriedade em toda a sua plenitude, estabelecendo que a necessidade de uso pelo "bem público" resultaria em prévia indenização". Vale dizer, à propriedade encontra-se garantida contra a ação do Estado, que teria que indenizar previamente ao proprietário acaso tivesse necessidade de utilizá-la. Trata-se de importante avanço, porque, como sabido, 16 anos antes, a Família Real Portuguesa, fugindo de Napoleão, ao chegar, primeiro a Salvador, e depois e definitivamente ao Rio de Janeiro, desalojou tantas moradias quanto necessárias, para acomodar a Corte em fuga.

Por fim, o inciso XXVI, ainda do art. 179, trata da assegurar aos "inventores" a "propriedade das suas descobertas, ou de suas produções", estabelecendo que a lei assegurará um "privilégio exclusivo temporário".

É evidente que embora tenha sido elaborada em um ambiente de feições quase absolutistas e outorgado ao Imperador poderes que se poderia dizer extra constitucionais, como o de controlar os demais Poderes, ainda assim, a Constituição de 1824 deve ser celebrada, seja pela razão única de ser uma Lei Fundamental, que, com erros e acertos, promoveu o Brasil ao seleto rol de países com Constituição escrita, organizando o Estado e procurando promover direitos e garantias ao cidadão.

Como o presente trabalho não pretende, e nem poderia tecer considerações sobre cada aspecto das Constituições aqui comentadas, pode-se dizer que no que diz respeito ao direito de propriedade, a Constituição de 1824 cumpriu um script mínimo e por isso merece ser festejada.

\section{CONSTITUIÇÃO DE 1891}


Sobre a queda do Imperador Pedro II e, principalmente, sobre o amanhecer da República, relevante o testemunho de João Mangabeira, jurista, político, que ao escrever a biografia de Rui Barbosa produziu o seguinte texto:

Em vez do poder, cercado de áulicos, preferiu ficar sozinho, no ostracismo, mas abraçado com a sua ideia. E, daí por diante, no Diário de Notícias, fuzila e troveja todos os dias. E, em cinco meses, raio sobre raio, inflama o ambiente, abrasa o Exército, sidera o Gabinete, arrasa o Império. Nem era senão por isto que a 9 de novembro, lhe dizia Benjamin Constant: "O seu artigo de hoje Plano contra a Pátria - fez a República e nos convenceu da necessidade imediata da Revolução.” (MANGABEIRA, 1999, p. 43)

Golpeada a Monarquia em novembro de 1889 e determinado o exílio da família Real, o novo Regime Republicano se fez presente, do ponto de vista legal, com o Decreto ${ }^{\circ} 1$, de 15 de novembro de 1889, que "institucionalizou” a República, a Federação e estabeleceu as bases mínimas do governo provisório, assinado por Deodoro da Fonseca e Rui Barbosa, entre outros.

Do ponto de vista formal ${ }^{8}$ a primeira Constituição republicana data de 1891, e durou quase meio século, 43 anos e cinco meses, para ser mais preciso. Ela foi o que se espera de uma Constituição, inovou em diversos aspectos, não só porque passou a regular uma República, mas porque incorporou "novidades" como a Forma Federativa de Estado, o sistema bicameral com o Senado representando o Estado, uma Corte Suprema para resolver os conflitos entre os entes federados e, por fim, ousou ao prever o controle judicial de constitucionalidade das leis, algo que sequer a Constituição dos Estados Unidos de 1787 - sua única e maior inspiração - estabeleceu explicitamente.

Como se sabe o controle de constitucionalidade nos Estados Unidos é fruto de construção jurisprudencial, assentada no caso Marbury v. Madison, fruto da criatividade do Chief Justice John Marshall, decidido em 1803. Marshall decidiu o caso e pronunciou a inconstitucionalidade que ampliou a competência da Suprema Corte sob intensa pressão, inclusive de impeachment; confira-se, em termos: "Marshall offered to abandon

\footnotetext{
${ }^{8}$ Formal porque na prática os decretos editados no dia e nas semanas que se seguiram à Proclamação da República tinham natureza constitucional, materialmente constitucionais.
} 
judicial supremacy in the interpretation of the Constitution in return yo abandon judicial supremacy um the interpretation of the Constitution in return for security against impeachment" (LOCKHART et al, 1996, p. 8).

Foi na vigência da Constituição de 1891 que se desenrolou a "Revolução de 30", que, em um certo sentido, tem origem remota e parcial em uma invasão de propriedade. Deu-se em 1930 mesmo quando Polícia do Estado da Paraíba, então governada por João Pessoa, invadiu a propriedade de um opositor político tendo acesso a cartas íntimas desse opositor com sua amante. O teor foi publicado no jornal do Estado e, em represália, João Dantas atirou e matou João Pessoa (então candidato a vice-presidente na chapa de Getúlio Vargas) em Recife, acontecimento que resultou no estopim da Revolução que mudaria a história do país (BALEEIRO, 2012, p. 52)

A Constituição de 1891 assegurava, art. 72, que os "brasileiros e estrangeiros residentes no país à inviolabilidade dos direitos concernentes à liberdade, à segurança individual e à propriedade”. Observe que o art. 179 da Constituição de 1824 não estendia essa proteção aos estrangeiros, limitava-se aos brasileiros. O $\S 11$ reproduz, com outras palavras, o inciso VII do art. 179 da Constituição de 1824, estabelecendo a inviolabilidade e acrescentando a expressão "sem consentimento do morador".

Por fim, ainda no art. 72, § 17, o Texto constitucional se ocupa de assegurar a "plenitude" da propriedade, ressalvando a possiblidade de "desapropriação por necessidade, ou utilidade pública, mediante indenização prévia". O imposto sobre "transmissão" da propriedade era da competência exclusiva do Estado, art. $9^{\circ}, \S 3^{\circ}$.

Como se vê, a Constituição que instituiu os "Estados Unidos do Brasil" dedicou generoso espaço ao direito de propriedade, inclusive inovando um pouco com relação ao primeiro texto constitucional, consoante se demonstrou.

\section{A CONSTITUIÇÃO DE 1934}


Trata-se, a Constituição de 1934, da mais breve Lei Fundamental do país e, no mundo, seguramente se encaixa entre as que tiveram vigência mais curta. Curiosamente sua elaboração foi longa, se considerada a "Subcomissão do Itamarati" (embora o nome oficial fosse "Subcomissão elaboradora do Anteprojeto 1932/1933"), grupo de juristas designado pelo Decreto $\mathrm{n}^{\circ} 22.040$, de $1^{\circ}$ de novembro de 1932, assinado por Getúlio Vargas. Essa Subcomissão elaboraria (como efetivamente elaborou) um anteprojeto de Constituição para posteriormente ser debatido na Constituinte, este compromisso getulista, consequência direta da Revolução de 32. Sobre a Comissão do Itamarati oportuno o registro de Gargarella:
"A Constituição de 1934 foi inspirada principalmente pela Constituição de Weimar. O documento foi originalmente redigido pela chamada Comissão Ita- marati, que reuniu muitos doutrinadores e políticos brasileiros. Entre outros membros, a Comissão incluía Afrânio Melo Franco, Carlos Maximiliano, José Américo de Almeida, Temístocles Cavalcanti e, talvez mais significativa- mente, João Mangabeira”. Tradução livre (GARGARELLA, 2013, p. 116)

Também é sobre essa Constituinte/Constituição que o notório e incontornável jurista Hans Kelsen elaborou parecer sobre a natureza do poder constituinte, uma vez que fora convidado pela revista brasileira "Política: revista de direito público, legislação social e economia", para se posicionar sobre o decreto que regulava o fundamento da Assembleia Nacional Constituinte de 1933-1934 (SIQUEIRA, 2015, p. 348-374).

É nela que surge o Mandado de Segurança, como instrumento genuinamente brasileiro, de feição civil, com a finalidade de oferecer à sociedade uma resposta célere para ilegalidades de natureza não penal. Surge justamente como sugestão de João Mangabeira na Comissão do Itamarati.

Influenciada pelo Movimento, por assim dizer, "mundial" que clamava por constituições que acolhessem direitos sociais, a de 1934 cumpriu bem esse papel, e nisso se inspirou na Constituição do México (1917) e de Weimar (1919), sendo até desnecessário listar as conquistas sociais da Constituição de 1934, porquanto extrapolaria a finalidade deste artigo. A redação do art. 113 diz muito sobre a natureza da Constituição de 1934 
e sua marcante preocupação social: "A ordem econômica deve ser organizada conforme os princípios da justiça e as necessidades da vida nacional, de modo que assegure a todos uma existência digna do homem. Dentro desses limites é garantida a liberdade econômica".

Nesse sentido o documento de 1934 lançou um olhar mais detalhista sobre a propriedade, contemplando situações que não foram tratadas nas Constituições anteriores.

Tome-se o exemplo do art. 114, inovador sob todos os aspectos. Garante, no $\mathrm{ca}$ put, o direito de propriedade, mas faculta à lei dizer o "conteúdo" e os "limites" desse direito. $\mathrm{O} \S 1^{\mathrm{a}}$ desse artigo, de forma absolutamente pioneira para uma Constituição Federal brasileira, estabelece que "a propriedade tem, antes de tudo, uma função social e não poderá ser exercida contra o interesse coletivo". Com um pouco de exagero interpretativo, poder-se-ia dizer que esse dispositivo não envergonharia a Constituição Soviética de 1918, embora, é claro, tenha sido elaborado em um país capitalista, ciente da importância de garantir a função social da propriedade, o que fez com maestria.

O parágrafo seguinte, o $2^{\mathrm{a}}$, é dedicado à expropriação, "por utilidade pública ou interesse social", "mediante prévia e justa indenização paga em dinheiro, ou por outra forma estabelecida em lei especial aprovada por maioria absoluta dos membros da Assembleia.

Tratou da usucapião no art. 116, estabelecendo que "aquele que, por cinco anos ininterruptos, sem oposição, nem reconhecimento de domínio alheio, possui um trecho de terra e a tornou produtiva pelo trabalho, adquire por isto mesmo a plena propriedade do solo, podendo requerer ao juiz que assim o declare por sentença”. Aqui um cotejo com o art. 72, § 17, da Constituição de 1891, que limitava a perda da propriedade à hipótese de desapropriação, de modo que nessa seara a de 1934 criou uma nova categoria constitucional, desconhecida dos textos fundamentais anteriores.

Estabeleceu (art. 116, $\S 1^{\circ}$ ) que "ficarão proprietários gratuitos das terras devolutas, onde têm benfeitorias, seus atuais posseiros, se forem nacionais", vale dizer, mais uma medida de caráter social, considerando o grande número de pessoas, famílias, no 
Brasil que detinham (detém) a posse e enfrentavam (enfrentam) dificuldade de toda ordem para regularizam, tornando-se assim proprietários. É curioso que não tenha fixado prazo caracterizar a condição de posseiro. Por certo poder-se-ia utilizar aquele estabelecido para a usucapião, de modo que andou bem a Constituição ao admitir a prescrição aquisitiva da posse.

Outro, por assim dizer, grande momento da Constituição de 1934 encontra-se estampado no art. 118, que humaniza as execuções e as falências, desde que não fraudulentas. Referido artigo tinha um objetivo explícito e direto: proibir se reduzisse o devedor à miséria: "Na execução, ou na falência não fraudulenta, não se poderá reduzir à miséria o devedor. A lei, ou na sua falta o juiz, providenciará a tal respeito."

Digno de nota que o artigo 118, caput, para além de proibir seja reduzido à miséria o devedor, outorga enorme poder ao juiz ao conferir a ele as condições para, ainda que na falta da lei, usar de meios (por óbvios constitucionais) para evitar que o devedor seja reduzido à miserabilidade. Merece destaque essa passagem: "ainda que na falta da lei", vale dizer, o Constituinte, nesse aspecto, procurou assegurar que o devedor não fosse submetido a tratamento vexatório, e, nesse sentido, autorizou o juiz a utilizar, em caso específico e diretamente nominado, de princípios gerais do direito de modo a atingir o desiderato constitucional.

$\mathrm{O} \S 1^{\circ}$ do art. 118 inaugura, no palco constitucional, a impenhorabilidade da casa da "pequena valia que servir de morada ao devedor e sua família, se ele não tiver outros haveres" e diz $\left(\S 2^{\circ}\right)$ também ser impenhorável, "nos mesmos termos”, a "propriedade rural destinada a prover a subsistência do devedor e sua família".

Na parte dedicada às condições do trabalho, art. 124, a Constituição estabeleceu $\left(\S 7^{\circ}\right)$ que a pequena propriedade deveria ser favorecida pela legislação agrária, facultando ao poder público expropriar os latifúndios, se houver conveniência de os parcelar em benefício do cultivador, ou de os explorar sob forma cooperativa.

Se é verdade que a constituição é o Estatuto Jurídico do Fenômeno Político, frase que se atribui a J.J. Gomes Canotilho, conforme recorda Lamego Bullos (1996, p. 25), 
a Lei Fundamental de 1934 bem demonstra a precisão, o acerto dessa frase do grande constitucionalista português.

\section{A CONSTITUIÇÃO DE 1946}

Atribui-se ao então Deputado Hermes Lina, um dos 37 membros da Comissão de Constituição, igualmente conhecida como "Grande Comissão", a afirmação, na primeira sessão, de que que "a obra seria mais de restauração do regime destruído pelo golpe de 1937" (BALEEIRO; SOBRINHO, 2012, p. 10). Ele se referia à Constituição que começava a ser elaborada, com a qual se pretendia romper em definitivo com o regime constitucional que vigera de 1937 a 1945.

A inviolabilidade do direito à propriedade encontra-se estampada no art. 141 do Texto de 1946, e nele está dito que "a Constituição assegura aos brasileiros e aos estrangeiros residentes no país a inviolabilidade dos direitos concernentes à vida, à liberdade, à segurança individual e à propriedade", para em seguida elencar nos parágrafos alguns desses direitos. Digno de registro que enquanto a de 1946 utiliza a expressão a "Constituição" assegura aos brasileiros, a de 1934 usou a "União" assegura aos brasileiros (art. 102, caput), o que, aos olhos de hoje, não se afigura como uma redação muito apropriada.

O artigo 141 ( $(16)$ da Lei Fundamental de 1946 garante o direito de propriedade, "excetuando a hipótese de desapropriação por necessidade ou utilidade pública, ou por interesse social, mediante prévia e justa indenização em dinheiro." Ainda nesse parágrafo 16 a Constituição se ocupa de relativizar o direito de propriedade no "caso de perigo iminente, como guerra ou comoção intestina" em que as autoridades "competentes poderão usar da propriedade particular, se assim o exigir o bem público, ficando, todavia, assegurado o direito a indenização ulterior."

Enquanto a Constituição de 1934 associou o termo "social" a expressões como "função", "interesse" (art. 114), "proteção" (at. 124), "progresso" e "assistência" (art. 127), a de 1946 inovou ao estabelecer "bem-estar social" (art. 147, caput), exigido que 
a uso da propriedade fosse condicionado a ele (bem-estar), para, em seguida, no mesmo caput, estabelecer que "a lei poderá, com observância do disposto no art. 141, $\S 16$, promover a justa distribuição da propriedade, com igual oportunidade para todos. "

A usucapião prolabore, tratado no art. 116 da Constituição de 1934, veio com roupagem diferente na Constituição de 1946, consoante se extrai do $\S 3^{\circ}$ do art. 156 :

$\S 3^{\circ}$ Todo aquele que, não sendo proprietário rural nem urbano, ocupar, por dez anos ininterruptos, sem oposição nem reconhecimento de domínio alheio, trecho de terra não superior a vinte e cinco hectares, tornando-o produtivo por seu trabalho e tendo nele sua morada, adquirir-lhe-á a propriedade, mediante sentença declaratória devidamente transcrita.

Digno de nota que o Constituinte de 1946 estabeleceu regras mais duras para esse tipo de usucapião: exigiu que o beneficiário não fosse proprietário rural ou urbano; que o trecho de terra não fosse superior a vinte e cinco hectares e, por fim, que tivesse nele sua "morada". Conforme se verá adiante, a Constituição de 1988 foi mais generosa, ou compreensiva. No art. 191 ela reduz o prazo para cinco anos ininterruptos e amplia para cinquenta hectares, mantendo a exigência da morada, que ela preferiu chamar de moradia. Convém lembrar que este trabalho não analisou os Textos Constitucionais de 1937, 1967/69, de modo que o cotejo da de 1946 é feito, neste caso, diretamente com a de 1988 .

Por fim, no que diz respeito à propriedade na Constituição de 1946 , o artigo $7^{\circ}$ do Ato das Disposições Constitucionais Transitórias, aqui reproduzido a título de curiosidade: "Art. $7^{\text {o }}$ Passam à propriedade do Estado do Piauí as fazendas de gado do domínio da União, situadas no Território daquele Estado e remanescentes do confisco aos jesuítas no período colonial".

Como se sabe os jesuítas foram expulsos de Portugal e de suas colônias por volta de 1759, por ato do Marquês de Pombal, fruto de intrigas e desconfianças próprias de regimes absolutistas. O que chama à atenção é que quase dois séculos depois a Constituição brasileira de 1946 trate do tema para disciplinar a propriedade de terras dos desterrados. 


\title{
9. A CRIAÇÃO DO BANCO NACIONAL DE HABITAÇÃO
}

Meses antes de promulgada a Constituição de 1946 o governo federal criou a Fundação da Casa Popular (FCP), através do Decreto-Lei no 9.218, de 19 de maio de 1946. Entre outras a FCP tinha por finalidade a "proporcionar a aquisição ou construção de moradia própria, na zona urbana ou rural, a brasileiros e a estrangeiros com mais de dez anos de residência no país" (VALADARES; HOFFMANN, 2009). Entretanto, por depender de "doações" do governo a FCP logo enfrentou inúmeras problemas que dificultaram seu papel e consolidação como agente incumbido de desenvolver programas habitacionais.

Oportuno transcrever parte do texto de autoria de Lícia Valadares e Andrea Hoffmann sobre a política habitacional iniciada nas vésperas da promulgação da Constituição de 46:

\begin{abstract}
Estima-se em 120 mil o total de unidades providas pela FCP, institutos e outros órgãos que promoveram a habitação no período entre as décadas de 1930 e 1964 (ano em que foi concomitantemente extinta a FCP e criado o BNH). Os poucos autores que analisaram a intervenção do Estado na área habitacional neste período mostram que é preciso situá-la dentro da política trabalhista do período Vargas e sugerem que a moradia, transformada em uma das vantagens concedidas pelo Estado a determinadas categorias de trabalhadores urbanos, serviu de instrumento de cooptação e controle dos segmentos da classe trabalhadora, de cujo apoio o Estado necessitava (VALADARES; HOFFMANN, 2009)
\end{abstract}

Como se vê durante largo espaço de tempo a política habitacional no Brasil esteve atrelada à política partidária, situação que, pouco mais, pouco menos, permanece até os dias atuais.

A Fundação da Casa Popular foi sucedida pelo Banco Nacional de Habitação (BNH), instituído pela Lei n 4.380, de 21 de agosto de 1964 que também criou o Plano Nacional da Habitação. Sediado no Rio de Janeiro o BNH durou até 21 de dezembro de 1986, data em que foi extinto pelo Decreto-Lei n ${ }^{\circ}$ 2.291, do Presidente José Sarney. Esse ato normativo estabeleceu que as atividades do banco fossem absorvidas pela Caixa 
Econômica Federal e pelo Banco Nacional do Desenvolvimento Econômico e Social (BNDES). Considerando ter sido criado por Lei, a extinção por Decreto-Lei suscitou certa polêmica na época, contudo, o ato em si não restou anulado pela Justiça.

\section{CONSTITUIÇÃO DE 1988}

Nenhuma outra Constituição brasileira lançou um olhar tão demorado e profundo sobre a posse e a propriedade como a Constituição de 1988, elaborada após um processo constituinte que teve início em 1986, com a eleição de novembro daquele ano. Eleitos, Deputados e Senadores, a partir de 1987 até outubro de 1988 elaborariam aquela que ficou conhecida, quando de sua promulgação, a "Constituição Cidadã", termo que se atribui ao Deputado (Doutor) Ulisses Guimarães, Presidente da Assembleia Nacional Constituinte.

Sendo a primeira Constituição democrática da história constitucional brasileira a se referir ao termo "moradia", inclusive alçando-o a patamar de Direitos e Garantias Fundamentais, no Capítulo dedicado aos "Direitos Sociais" (arts. $6^{\circ}$ a 11), impõe-se, aos propósitos do presente artigo, sejam alinhavadas considerações mais espaçadas sobre a moradia enquanto valor constitucionalmente assegurado e protegido. Com efeito, como visto, a Constituição de 1946 se referiu a "morada", e, embora sinônimas, a de 46 o fez de forma tímida, sem o alcance e a importância que a de 1988 emprestou ao termo. A redação original da Constituição Federal de 1988 não comtemplava a "moradia" como “direito social". O acréscimo foi objeto da Emenda Constitucional n 26/2000.

Antes, porém, é necessário elencar alguns princípios e regras constitucionais albergadas pelo Estatuto Fundamental de 1988 relativas à propriedade. E aqui será feito em passant. Primeiro porque a vigente Constituição é muito generosa no que diz respeito à propriedade, com várias citações, algumas delas já objeto de comentários quando da análise das Constituições anteriores, o que torna despiciendo reiterar o que já foi dito. Segundo porque tais comentários, além de redundantes, tornaria o presente artigo mais 
extenso do que ele pretende e deve ser. Terceiro porque a análise da Constituição de 1988 será feita, dentro do possível, com ênfase para a "moradia".

$\mathrm{O}$ art. $5^{\circ}$, principal referência dos direitos e garantias fundamentais, consagra a propriedade, como fizeram as Constituições de 1934 e 1946. E o faz no caput e em mais cinco incisos (XXII, XXIII, XXV, XVI e XXIX). Ao definir as bases da "Política Urbana", a Constituição de 1988 estabeleceu, no $\S 2^{\circ}$ do art. 182, que "a propriedade urbana cumpre sua função social quando atende às exigências fundamentais de ordenação da cidade expressas no plano diretor." A esse dispositivo se juntam outros como a progressividade do IPTU ( $\S 4^{\circ}$, II, do art. 182) ou o "tratamento especial” à propriedade produtiva, estampada no parágrafo único do art. 185.

O direito à moradia encontra-se contemplado no art. $6^{\circ}$, caput, e no inciso IV, que vincula o valor do salário mínimo ao atendimento às "necessidades vitais básicas", entre elas a moradia. Mais à frente, arts. 183 e 191, o Texto Fundamental vincula, respectivamente, a usucapião urbana e rural a que o beneficiário tenha "moradia" no imóvel.

Paulo Carmona, citando o grande arquiteto francês, Corbusier, lembra que "que habitar é uma necessidade intrínseca à existência do ser humano, razão pela qual o direito à habitação é inerente à vida. Daí o conceito de Le Corbusier de que a moradia é o local onde o homem ou a família "vive, dorme, anda, ouve, vê e pensa" (CARMONA, 2015, p. 266)

Mais adiante o mesmo autor lembra que direito de propriedade e direito de moradia não se confundem, pois a moradia é objeto de direito autônomo, com âmbito de proteção e objeto próprios, podendo ser requisito para a aquisição da propriedade, como no caso da usucapião especial constitucional (art. 183).” E acrescenta, com precisão, que o "direito à moradia opera-se como garantia a um lugar adequado para proteger-se a si próprio e a sua família contra as intempéries, independentemente do título ou da forma como se opera tal direito" (CARMONA, 2015, p. 267).

\section{RELEVÂNCIA DO SIGNIFICADO DA "MORADIA"}


Alexandre Shimizu Clemente, conseguiu sintetizar com rara precisão a ideia e a relevância do significado de "moradia", in verbis:

Um indivíduo deixa sua condição de sujeito singularmente considerado, a partir do momento em que a coletividade em que habita ganha estruturas organizacionais capazes de garantir uma convivência pacífica e duradoura entre os seus componentes. É neste momento também que ele deixa a condição de indivíduo, pois surge -concomitantemente a este rudimentar arcabouço social - as noções de cidadania, ou seja, ele passa a ser um cidadão, haja vista a formação de um vínculo pessoal entre ele e o que se constituirá em Estado. Um dos primeiros elementos que se estabelece nesta "organização", sem dúvida, é o espaço próprio para aquele indivíduo e seus pares. Exsurge, então, a ideia de moradia. (CLEMENTE; FREITAS)

A observação supra parece se harmonizar com um dos livros mais significativos de Jorge Amado, “Capitães da Areia”, publicado nos agitados anos 1930, pouco antes do Golpe de Estado de 1937, período mais obscuro da "Era Vargas". Nele o escritor baiano de fama internacional procura demonstrar a falta de uma política de Estado em prol de menores de idade em situação irregular, sem família e sem "moradia" digna, definidos à época como "capitães da areia":

"Já por varias vezes o nosso jornal, que é sem duvida o órgão das mais legitimas assirações da população bahiana, tem trazido noticias sobre a atividade criminosa dos "Capitães da Areia", nome pelo qual é conhecido o grupo de meninos assaltantes e ladrões que infestam a nossa urbe. Essas creanças que tão cedo se dedicaram á tenebrosa carreira do crime não teem moradia certa ou pelo menos a sua moradia ainda não foi localisada. Como também a|nda não foi localisado o local onde escondem o produto dos seus assaltos que se tornam diários, fazendo jus a uma imediata providencia do juiz dos menores e do dr. Chefe de policia (AMADO, 1937, p. 21)

O texto ficcional (reproduzido com a vernáculo da época) é de um jornal relatando os crimes dos garotos e nele fica claro que a ausência de moradia e laços familiares contribuem para a delinquência. É interessante que um romance que se encaminha para completar um século, trate de um tema ainda tão presente (como bem demonstra a pesquisa de doutoramento do arquiteto Luiz Kohara, objeto de comentários mais à frente) no Brasil da primeira quadra do século XXI e sobre o qual a Constituição elevou à categoria de direito fundamental. 


\section{CONDIÇÕES DE MORADIA E DESEMPENHO ESCOLAR}

Há diversos trabalhos científicos de qualidade que demonstram a persistência do problema do déficit habitacional brasileiro. Entre eles merece destaque um de autoria de Luiz Tokuzi Kohara, intitulado "Relação entre as condições da moradia e o desempenho escolar: estudo com crianças residentes em cortiços. São Paulo-SP”. Trata-se de tese de defesa de Doutorado na Universidade de São Paulo (USP), defendida e aprovada em 2009. A introdução é bastante esclarecedora e merece ser parcialmente transcrita:

Esta tese estuda a relação entre as condições da moradia e o desempenho escolar de crianças residentes em cortiços. O estudo foi desenvolvido com alunos da quarta série, da Escola Municipal de Ensino Fundamental Duque de Caxias, localizada no Bairro do Glicério, distrito da Liberdade, região que possui grande concentração desse tipo de moradia. Para situar o objeto de estudo, os três primeiros capítulos do trabalho enfocam o problema da habitação, destacadamente, dos cortiços, a história de exclusão escolar das crianças pobres e o significado do espaço para as crianças.

Nos dois capítulos seguintes, é desenvolvido o objeto do estudo. Utilizou-se para isso, a metodologia qualitativa e posta em prática através de contato direto com grupos de pessoas selecionadas e visitas às moradias dos alunos. $\mathrm{O}$ trabalho conclui que o desempenho escolar das crianças pesquisadas é prejudicado pelas precárias condições de moradia. Finalizando, traz sugestões para as políticas públicas de moradia popular no centro da cidade e para a política da educação (KOHARA, 2009)

A Tese de Luiz Kohara traz números impressionantes. Segundo ele dados "da série PNADIS 2007 apontam que "54,606 milhões de pessoas residiam em moradia inadequada, representando 34\% dos 158,278 milhões de brasileiros" (KOHARA, 2009). O conceito de "inadequada" alcança "emprego de materiais não duráveis nas paredes e nos tetos, moradias superlotadas, serviço de esgoto inadequado e uso de água inadequada para o consumo."

O autor diz que "nos últimos 15 anos a população favelada cresceu $42 \%$, passando de 4,914 milhões em 1992, para 6,979 milhões em 2007." Nesse período houve 
uma melhora no serviço de água e captação de esgoto, contudo, conclui o autor, se referindo ao déficit de moradia, que "os dados apresentados pelo IPEA vêm reafirmar a dimensão do problema que havíamos relatado" (KOHARA, 2009).

A moradia é direito social de natureza constitucional e se apresenta como uma obrigação do Estado, indispensável à construção e manutenção da Cidadania. A pesquisa do Luiz Kohara empresta ainda mais relevância ao tema, porque demonstra o liame entre moradia digna e desempenho educacional, dois segmentos que o Brasil nunca foi bem e que se apresentam interligados e decisivos para o futuro do país.

\section{CONCLUSÃO}

Por qual razão trinta anos depois de promulgada a Constituição Federal de 1988, cinquenta e cinco anos depois da criação do Banco Nacional de Habitação (para não mencionar a Fundação da Casa Popular, ainda mais antiga), os problemas habitacionais no Brasil persistem e envergonham um país de dimensões continentais, fora do circuito de desastres naturais de grande envergadura (tufões, terremotos, vulcões, maremotos e pandemia)? Como justificar que a oitava economia do mundo, e que por um espaço razoável de tempo chegou à sexta posição, conviva com um déficit habitacional gigantesco, se, além de tudo isso (amplos espaços habitáveis, enorme fonte de recursos naturais e ausência de desastres da natureza), a sua Constituição Federal alçou o direito social à moradia à condição de cláusula de Direito Fundamental?

A evolução do direito de propriedade, a partir, e, desde as linhas tracejadas por Jefferson na Declaração de 1776, passando por importantes e simbólicos marcos, como a Constituição oriunda da Convenção da Filadélfia, de 1787, a Declaração francesa de 1789, e os sucessivos marcos constitucionais brasileiros, até a chegada da Constituição de 1988, dando preponderância à moradia como direito fundamental social, é algo que 
precisa se analisado desde um ponto de vista mais que simbólico, mas também da assinatura (e, portanto, da leitura dos propósitos), conforme Jacques Derrida ${ }^{9}$, para uma tentativa de enriquecer a discussão.

É forçoso reconhecer que não existem respostas simplistas para um problema tão complexo. Igualmente não existe uma única resposta, mas, talvez fosse correto dizer que a principal delas é a falta de planejamento de longo prazo associado a uma política pública de enfrentamento real do problema e o reconhecimento que o que se fez até 2020 não se mostrou eficaz para a solução dessa chaga que afeta o ser humano naquilo que lhe é mais fundamental: moradia digna para si e sua família. Sem moradia minimamente digna diversos outros direitos sociais não se sustentam, como a saúde, a educação e a felicidade a que se referiu a Declaração de Independência setecentista, referida nas primeiras linhas deste texto.

\section{REFERÊNCIAS}

AMADO, Jorge. Capitães da Areia. Rio de Janeiro: Livraria José Olímpio Editora, 1937 BALEEIRO, Aliomar. Coleção Constituições Brasileiras, v. II, 1891. Brasília: Gráfica do Senado, 2012, $3^{\mathrm{a}}$ ed.

BALEEIRO, Aliomar; SOBRINHO, Barbosa Lima. $3^{\text {a }}$ ed Coleção Constituições Brasileiras, v. V, 1946. Brasília: Gráfica do Senado, 2012.

BULLOS, Uadi Lamego. Teoria da Interpretação Constitucional. Revista de Direito Administrativo, Rio de Janeiro, jul/set. 1996, p. 25.

CARMONA, Paulo Afonso Cavichioli. A tutela do direito de moradia e o ativismo judicial. Brasília: Revista Brasileira de Políticas Públicas, vol 5, edição especial, 2015.

\footnotetext{
${ }^{9}$ DERRIDA, Jacques. Declarações de Independência. Trad. Thiago Aguiar de Pádua. Revista da AGU, v. 16, n. 2, p. 77-86, abr./jun. 2017; DERRIDA, Jacques. "Déclarations d'Independance”, In: Otobiographies: L'enseignement de Nietzsche et la politique du nom propre, Paris: Galilée, 1984, p. 13-32; DERRIDA, Jacques. Declarations of Independence. trad. Tom Keenan e Tom Pepper, New Political Science, 15 (1986), p. 7-15.
} 
CLEMENTE, Alexandre Shimizu. FREITAS, Riva Sobrado de. A Dimensão Humana do Direito à Moradia. http://www.publicadireito.com.br/conpedi/manaus/arquivos/anais/fortaleza/4099.pdf

CORRY, J. A. Elements of Democratic Government. New York: Oxford University Press. 1951.

DERRIDA, Jacques. Declarações de Independência. Trad. Thiago Aguiar de Pádua. Revista da $A G U$, v. 16, n. 2, p. 77-86, abr./jun. 2017;

DERRIDA, Jacques. “Déclarations d'Independance”, In: Otobiographies: L'enseignement de Nietzsche et la politique du nom propre, Paris: Galilée, 1984, p. 13-32;

DERRIDA, Jacques. Declarations of Independence. trad. Tom Keenan e Tom Pepper, New Political Science, 15, 1986.

GARGARELA, Roberto. Latin America Constitutionalism. New York: Oxford University Press, 2013,

KOCH, Adrienne e PEDEN William, "The Life and Selected Writings of Thomas Jefferson", New York: The Modern Library, 1998.

KOHARA, Luiz Tokuzi. Relação entre as condições da moradia e o desempenho escolar: estudo com crianças residentes em cortiços. São Paulo-SP”. Tese (Doutorado em Arquitetura e Urbanismo) São Paulo: Faculdade de Arquitetura e Urbanismo da Universidade de São Paulo, USP, 2009.

LOCKHART, William B.; KAMISAR, Yale; CHOPER, Jesse H.; SHIFFRIN, Steven H.; FALLON JR., Richard H. Constitutional Law. Cases-Comments-Questions. 8. ed. St. Paul:West Publishing Co, 1996.

MANGABEIRA, João. Rui, O Estadista da República. Brasília: Gráfica do Senado, 1999.

NOGUEIRA, Octaciano. Coleção Constituições Brasileiras, 1824. Brasília: Gráfica do Senado, 2012.

SILVA, José Afonso. Curso de Direito Constitucional Positivo, $13^{\text {a }}$ edição, São Paulo: Malheiros, 1997.

SIQUEIRA, Gustavo Silveira. “O parecer de Kelsen sobre a Constituinte brasileira de 1933-1934”. Direito \& Práxis, v. 06, n.11, 2015. 
SOUTO, João Carlos. Suprema Corte dos Estados Unidos: Principais Decisões, $3^{\mathrm{a}}$ edição São Paulo: Atlas., 2019.

VALADARES. Lícia do Prado. HOFFMANN, Andrea Ribeiro. Centro de Pesquisa e Documentação de História Contemporânea do Brasil (CPDOC). Fundação Getúlio Vargas. Verbete: Banco Nacional de Habitação. http://www.fgv.br/cpdoc/acervo/dicionarios/verbete-tematico/banco-nacional-da-habitacao-bnh

Data da submissão:10/04/2020

Data da primeira avaliação:23/07/2020

Data da segunda avaliação: 06/08/2020

Data da aprovação: 06/08/2020 